\title{
Study on Mechanical Behavior of Jurassic Frozen Sandstone in Western China Based on NMR Porosity
}

\author{
Maoyan Ma $\mathbb{D},{ }^{1}$ Yishun Huang, ${ }^{2}$ Guangyong Cao $\left(\mathbb{D},{ }^{1}\right.$ Jian Lin $\mathbb{D}^{1},{ }^{1}$ and Shiliang Xu $\mathbb{D}^{1}$ \\ ${ }^{1}$ Anhui Key Laboratory of Building Structure and Underground Engineering, Anhui Jianzhu University, Hefei 230601, China \\ ${ }^{2}$ Chendu JZFZ Architectural Design Co. Ltd., Hefei 230031, China \\ Correspondence should be addressed to Guangyong Cao; caogy1973@ahjzu.edu.cn
}

Received 18 October 2019; Accepted 27 November 2019; Published 30 April 2020

Guest Editor: Shaohui Wang

Copyright (c) 2020 Maoyan Ma et al. This is an open access article distributed under the Creative Commons Attribution License, which permits unrestricted use, distribution, and reproduction in any medium, provided the original work is properly cited.

Study of frozen rock mechanical properties is necessary for safe application of the artificial ground freezing method in excavation of Chinese western water-rich soft rock layers. Triaxial compression tests and NMR test for samples from the western Jurassic sandstone were performed to investigate rock mechanical properties affected by low temperature and confining pressure. The results show mechanical parameters such as peak strength, cohesion, internal friction angle, residual strength, and elasticity modulus increased with the decreasing temperature under stable pressure, and the above parameters increased with the increasing confining pressure at a certain temperature. In particular, the growth rate of the rock strength would decline when the temperature was below $-10^{\circ} \mathrm{C}$ in this study. Strength attenuation coefficients increased with the decreasing temperature, which indicated higher brittleness, whereas plastic characters got more obvious with the increasing confining pressure at a stable temperature. Furthermore, during the first two freezing stages, porosity decreased sharply with obvious increase of pore (crack) ice content, while porosity varied little at the third stage, which was the reason for the growth rate of rock strength declining with continuous low temperature from microcosmic point of view.

\section{Introduction}

During the "Thirteenth Five-Year Plan" period, China will reduce the total coal production of eastern, central, and northeastern areas and promote the base construction of western coal fields gradually. Western China, including Inner Mongolia, Shanxi, Xinjiang, Ningxia, Gansu, and other provinces and autonomous regions, has a huge amount of coal resources. Coal beds mainly distributed in Jurassic and Cretaceous water-rich soft rock layers are weakly cemented. Moreover, water-rich soft rock layers are ready to hydrolyze with sharply dropped strength when exposed to hydrodynamic erosion. Meanwhile, coal-bearing layers here usually have large unit water inflow and high permeability [1-6]. Therefore, artificial ground freezing method is still the key method used in the mine construction of Western China. At low temperature, rocks show mechanical properties which are different from those at normal temperature and mechanical properties at low temperature are the basic data of freeze sinking, so the mechanical properties of the frozen soft rock in Jurassic and Cretaceous layers in Western China are important to guide effectively the design and construction of frozen wells of western mines. It is also critical to the safety of other cold area engineering construction. Therefore, more and more attention has been paid to the mechanical properties of frozen rocks.

Studies of mechanical properties of rocks at low temperature have been widely carried out with the large number of artificial freezing engineering and other geotechnical engineering actions in cold regions. It is revealed that the rock with different water saturation has different performance in uniaxial compressive strength, tensile strength, and fracture toughness at low temperature [7-11]. Different kinds of rocks such as red sandstone, shale, and silty mudstone show different mechanical performance at different temperature $[12,13]$. Loading rate also has effect on the mechanical properties of frozen rocks [14]. Mechanical properties of coal, sandstone, and sandy mudstone have been studied considering different pressure and temperature [15-22]. Besides, confining pressure and temperature, the 
impact of cracks on the mechanical properties of the frozen rock should be considered [23]. Due to the extremely rich resources in Western China, the mechanical properties of rocks from Western China have always been one of the research hotspots. A large number of studies on Cretaceous rocks from Western China have shown that temperature, confining pressure, water-saturated state, and other conditions can lead to different mechanical properties and damage processes [24-28]. Recently, acoustic emission technology has been used to investigate the cause of physical mechanics properties change of the frozen rock, and it is proved that the damage process of the frozen rock is related to the freezing process [29].

In general, mechanical properties of the rocks at low temperature vary with lithology, microstructure of rocks, and water content. Due to the limitations of instrumentation and detection technology, it is still impossible to understand the physical and mechanical properties of rocks at low temperature comprehensively and accurately now. Systematic research studies on mechanical properties of frozen rocks are still necessary. In addition, former studies are mainly focused on the mechanical properties of Cretaceous frozen rocks of Western China. Studies on that of western Jurassic rocks are also necessary. Therefore, the mechanical properties of the Jurassic sandstone in Western China were studied under different conditions considering temperature and confining pressure in the current paper. The effects of temperature and confining pressure on the mechanical properties of Jurassic rocks were investigated, and an explanation was given from a microcosmic point of view based on the NMR test.

\section{Materials and Methods}

2.1. Sample Preparation. The rock samples were obtained from the Jurassic Zhiluo Formation in Balasu mine, Yulin city, Shaanxi province, China. Samples were standardized to the size of $\Phi 50 \times 100 \mathrm{~mm}$ (Figure 1). A HC-F800 acoustic wave tester was used to make sure that samples for each testing group were in good consistency, and the difference of the longitudinal wave velocity was less than $0.5 \mathrm{~km} / \mathrm{s}$. The physical parameters of rock sampling depth and normal temperature are shown in Table 1.

Clastic grains of the sample are mainly highly sorted feldspar, quartz, and mica with poor roundness cemented by clay minerals and the secondary enlargement of quartz (Figure 2). Feldspar is mainly alkaline feldspar with high level kaolinization. The contact forms are mainly point-tosurface and surface-to-surface. The rocks are poor in their stability.

2.2. Test Scheme and Process. Triaxial compression tests were performed under different conditions with a temperature of $25^{\circ} \mathrm{C},-5^{\circ} \mathrm{C},-10^{\circ} \mathrm{C}$, and $-15^{\circ} \mathrm{C}$ and confining pressure of 0,4 , 6 , and $8 \mathrm{MPa}$, respectively. Three rock samples were tested under each temperature and pressure condition, and the results from the three samples were averaged. Meanwhile, one sample was tested for NMR porosity at different temperatures of $25^{\circ} \mathrm{C},-5^{\circ} \mathrm{C},-10^{\circ} \mathrm{C}$, and $-15^{\circ} \mathrm{C}$. The test process was as follows:

(1) Immerse the samples in a closed water cylinder without air for 24 hours.

(2) Place the water-saturated rock samples in a low temperature thermostat with preset temperature $\left(25^{\circ} \mathrm{C},-5^{\circ} \mathrm{C},-10^{\circ} \mathrm{C}\right.$, and $-15^{\circ} \mathrm{C}$, respectively), and set the freezing rate at $1^{\circ} \mathrm{C} / \mathrm{h}$.

(3) After freezing for 48 hours at a specified temperature, cover the samples with rubber and put them into the MTS-816.02 electro-hydraulic servo mechanical test system for triaxial compression tests under different confining pressure.

MesoMR23-060H-I was used for NMR microstructure analysis. The samples were maintained at $1 \mathrm{MPa}$ in the vacuum pressure saturation equipment and saturated for $24 \mathrm{~h}$ before they were put into the NMR equipment to measure the changes of porosity at $25^{\circ} \mathrm{C},-5^{\circ} \mathrm{C},-10^{\circ} \mathrm{C}$, and $-15^{\circ} \mathrm{C}$.

\section{Results and Analysis}

3.1. Results under Different Conditions of Temperature and Confining Pressure. Stress-strain curves of the Jurassic sandstone under different conditions considering temperature and confining pressure were obtained by compression tests (Figure 3). It is observed that the failure process of Jurassic sandstone has four stages which include compaction stage, linear elasticity stage, yield stage, and failure stage. Confining pressure and temperature have great effects on the strength. Under stable confining pressure, the strength of the rock increases with the decreasing temperature. With the reduction of temperature, the compaction stage can be shortened and the slope of the elastic stage increases, and then yield phenomenon becomes more and more unobvious, which means increases in elastic modulus and brittleness. At a specified temperature, with the increasing confining pressure, the compaction stage is shortened, the slope of the elastic stage increases, and rock strength increases, but the yield phenomenon before reaching the peak value is more and more obvious, which indicates that increasing confining pressure can lead to an increase in rock plasticity.

3.2. Fracture Patterns of Jurassic Sandstone. The development of cracks and joints in rocks has effect on fracture patterns. The fracture modes of some samples in tests are shown in Figure 4. There are three types of damage: (1) tension failure, which occurs in the same direction as the maximum principal stress (Figure 4(a)); (2) shear failure, which forms one or more shear failure surfaces along the diagonal direction (Figure 4(b)); and (3) coupled tension and shear failure (Figure 4(c)). Shear failure is the primary type of damage, and temperature affects the roughness of the shear surfaces. As the temperature decreases, the shear surfaces will become smoother. 


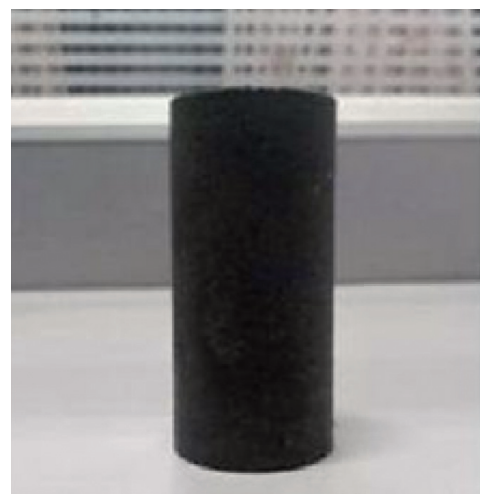

(a)

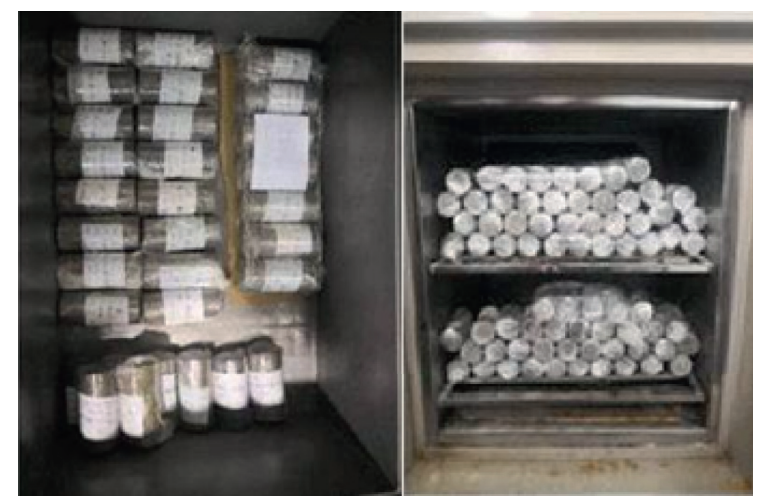

(b)

FIgURE 1: Rock samples: (a) standard rock sample and (b) sample preparation.

TABLE 1: Rock physical properties.

\begin{tabular}{lccc}
\hline Lithology & $\begin{array}{l}\text { Density } \\
\left(\mathrm{g} / \mathrm{cm}^{3}\right)\end{array}$ & Water content (\%) & Porosity (\%) \\
\hline Medium sandstone & 2.37 & 9.13 & 9.33 \\
\hline
\end{tabular}

\subsection{Strength Characteristics of Jurassic Sandstone at Low Temperature}

3.3.1. Peak Strength. Results of rock peak strength for the tests under different temperature and confining pressure are shown in Figure 5. Results from the test at $25^{\circ} \mathrm{C}$ are also shown for comparison. It is found that lower temperature leads to higher peak strength, while the peak strength growth rate declines at colder temperature. At the temperature of $-5^{\circ} \mathrm{C}$, the peak strength increases by $100.98 \%, 95.44 \%, 90.13 \%$, and $86.67 \%$, respectively, under the confining pressure of $0,4,6$, and $8 \mathrm{MPa}$ compared to that of $25^{\circ} \mathrm{C}$. The peak strength is nearly doubled under the confining pressure of $0 \mathrm{MPa}$. However, when the temperature is below $10^{\circ} \mathrm{C}$, the growth rate declines (Figure 5(a)). In addition, the peak strength shows a positive relation with the confining pressure at a stable temperature (Figure 5(b)). When confining pressure increases from 0 to $8 \mathrm{MPa}$, the peak strength increases by $39.13 \%, 34.81 \%$, and $37.43 \%$ at $-5^{\circ} \mathrm{C},-10^{\circ} \mathrm{C}$, and $-15^{\circ} \mathrm{C}$, respectively. It indicates that the strength of the Jurassic sandstone is affected by both low temperature and confining pressure.

3.3.2. Shear Strength. Shear failure is the main fracture mode of tested Jurassic sandstones, so values of the cohesion and internal friction angle can be calculated based on the Mohr-Coulomb criterion. The relation curves of maximum principal stress and minimum principal stress were fitted by test results, and the cohesion and internal friction angle are obtained as given in Table 2.

Cohesion and internal friction angle at different temperature are shown in Figure 6. The values of cohesion and internal friction angle of the Jurassic sandstone increase with the decreasing temperature. When the temperature decreases from $25^{\circ} \mathrm{C}$ to $-15^{\circ} \mathrm{C}$, the cohesion increases from $6.82 \mathrm{MPa}$ to $10.02 \mathrm{MPa}$ with an increment of $46.92 \%$. However, when the temperature reduces to about $-10^{\circ} \mathrm{C}$, the growth rate of cohesion slows down. The value of cohesion increases by $14.02 \%$ when the temperature decreases from $-5^{\circ} \mathrm{C}$ to $-10^{\circ} \mathrm{C}$, and only $2.84 \%$ when the temperature decreases from $-10^{\circ} \mathrm{C}$ to $-15^{\circ} \mathrm{C}$. In terms of the internal friction angle, it increases from $22.58^{\circ}$ to $28.99^{\circ}$ with an increment of $28.39 \%$ when the temperature decreases from $25^{\circ} \mathrm{C}$ to $-15^{\circ} \mathrm{C}$. Therefore, low temperature has more influence on cohesion than the internal friction angle of the Jurassic sandstone. In other words, pore (crack) ice plays a key role in enhancing cohesion of the rock at low temperature by cementing rock grains, which ultimately leads to the increase of the shear strength.

3.3.3. Residual Strength. Residual strength is shown in Figure 7. Under stable confining pressure, the residual strength of the Jurassic sandstone increases with the decreasing temperature and shows significant growth at subzero temperatures (Figure $7(\mathrm{a})$ ). When the temperature drops to $-15^{\circ} \mathrm{C}$ from $25^{\circ} \mathrm{C}$, the residual strength increases by $151.15 \%, 123.9 \%$, and $132.43 \%$, respectively, under the confining pressure of 4,6 , and $8 \mathrm{MPa}$. When the temperature drops to $-10^{\circ} \mathrm{C}$ from $-5^{\circ} \mathrm{C}$, the residual strength increases by $33.21 \%, 23.45 \%$, and $12.05 \%$, respectively, whereas when the temperature drops to $-15^{\circ} \mathrm{C}$ from $-10^{\circ} \mathrm{C}$, the residual strength increases by $22.38 \%, 21.11 \%$, and $11.75 \%$, respectively, under the confining pressure of 4,6 , and $8 \mathrm{MPa}$. Therefore, the growth rate of the residual strength slows down at colder temperature (below $-10^{\circ} \mathrm{C}$ ). Figure $7(\mathrm{~b})$ shows that the residual strength of the Jurassic sandstone increases when the confining pressure increases at a specified temperature. When the confining pressure rises from $4 \mathrm{MPa}$ to $8 \mathrm{MPa}$, the residual strength increases by $96.51 \%, 69.06 \%$, $42.21 \%$, and $29.86 \%$, respectively, at $25^{\circ} \mathrm{C},-5^{\circ} \mathrm{C},-10^{\circ} \mathrm{C}$, and $-15^{\circ} \mathrm{C}$.

\subsection{Deformation Characteristics of Jurassic Sandstone at Low Temperature}

3.4.1. Elastic Modulus. According to stress-strain curves (Figure 3), the elastic modulus under different conditions can be obtained as shown in Figure 8. Figure 8(a) shows that 


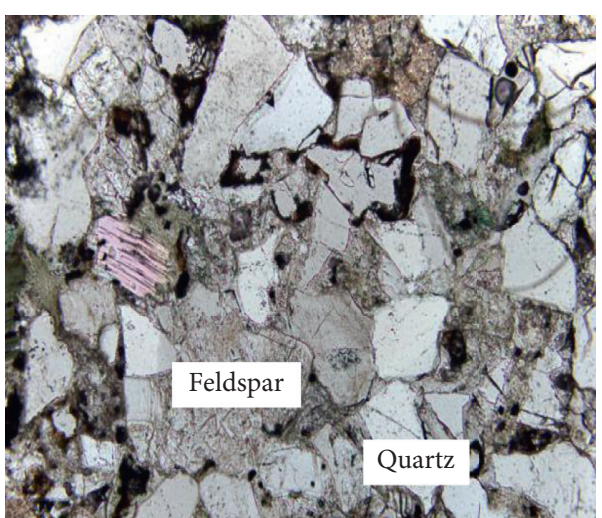

(a)

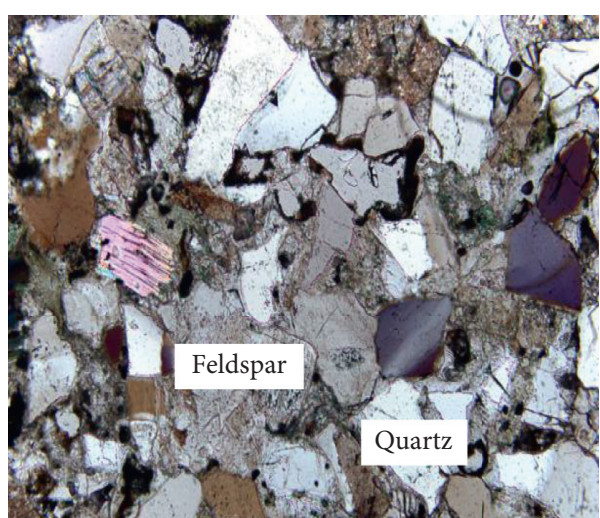

(b)

FIgURE 2: Microstructure of Jurassic sandstone (8x magnification): (a) plane polarized light, and (b) perpendicular polarized light.

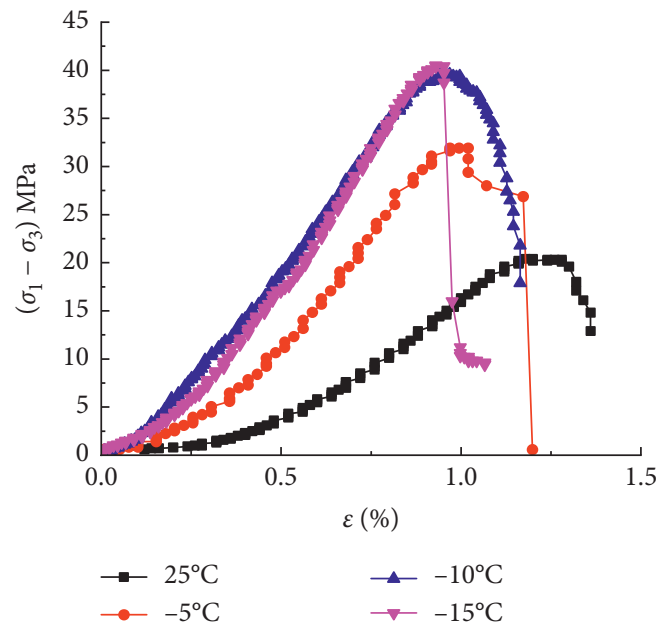

(a)

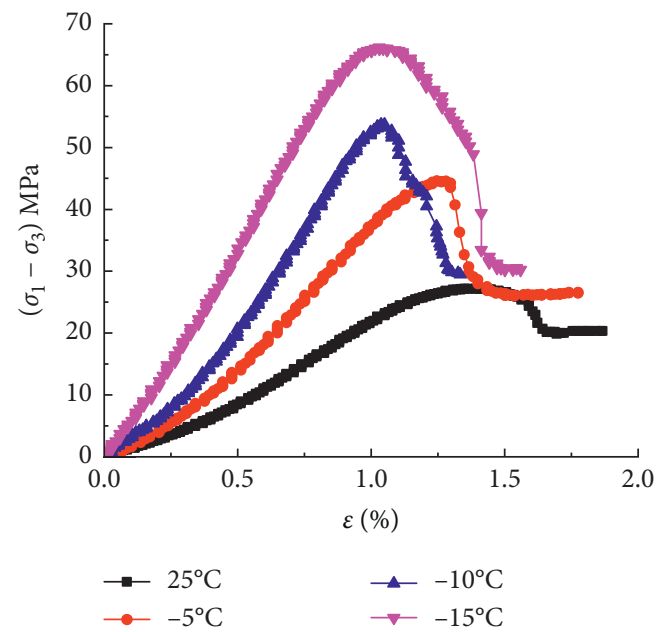

(c)

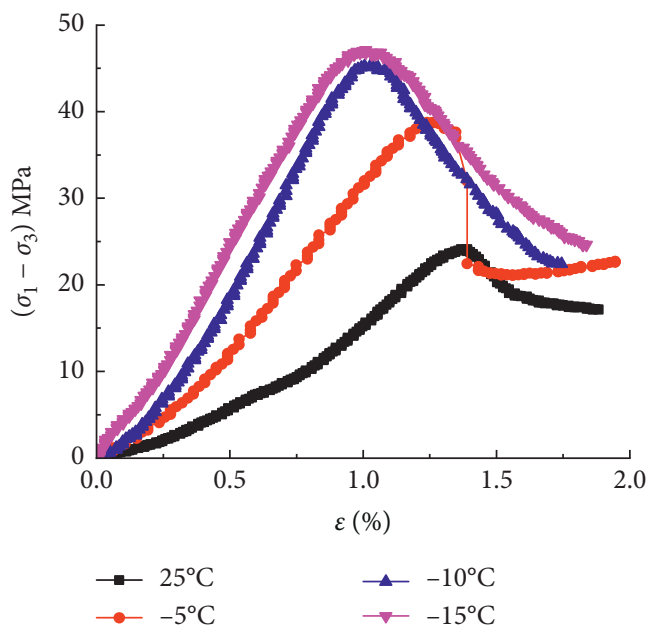

(b)

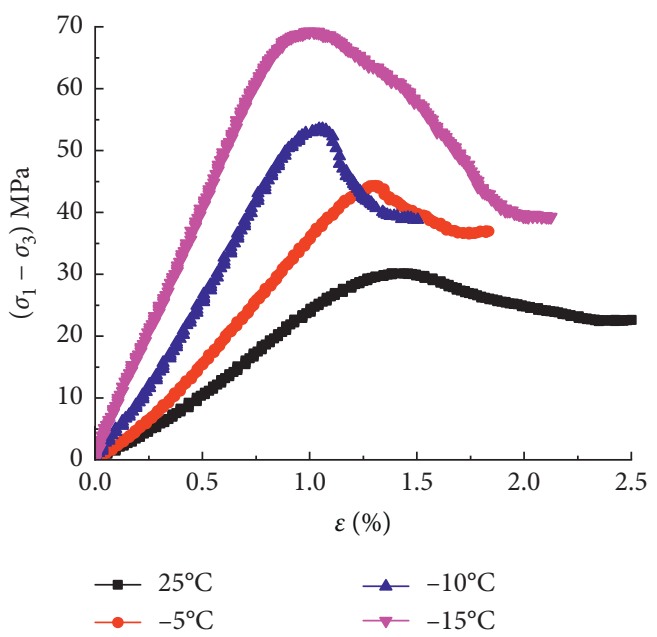

(d)

Figure 3: Stress-strain curves with different confining pressures: (a) $0 \mathrm{MPa}$, (b) $4 \mathrm{MPa}$, (c) $6 \mathrm{MPa}$, and (d) $8 \mathrm{MPa}$.

the value of elastic modulus is greatly affected by temperature. Under stable confining pressure, the elastic modulus gradually increases with the decreasing temperature, while the growth rate declines at colder temperature (below $10^{\circ} \mathrm{C}$ ). The elastic modulus increases by $175.49 \%$ when the temperature decreases from $25^{\circ} \mathrm{C}$ to $-5^{\circ} \mathrm{C}, 31.87 \%$ when the 


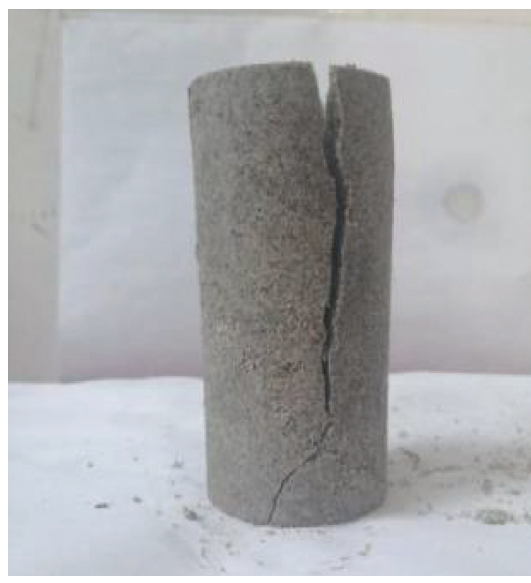

(a)

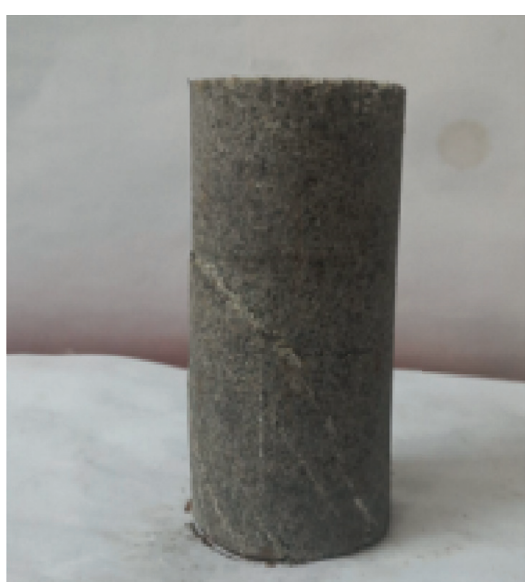

(b)

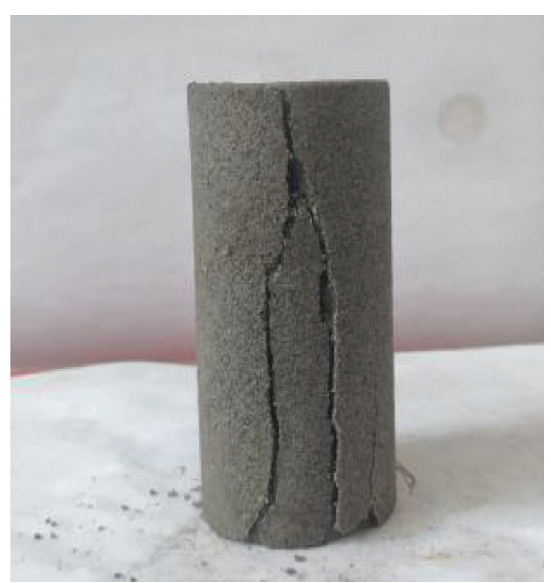

(c)

FIgURE 4: Fracture modes of samples: (a) tension failure, (b) shear failure, and (c) coupled failure.

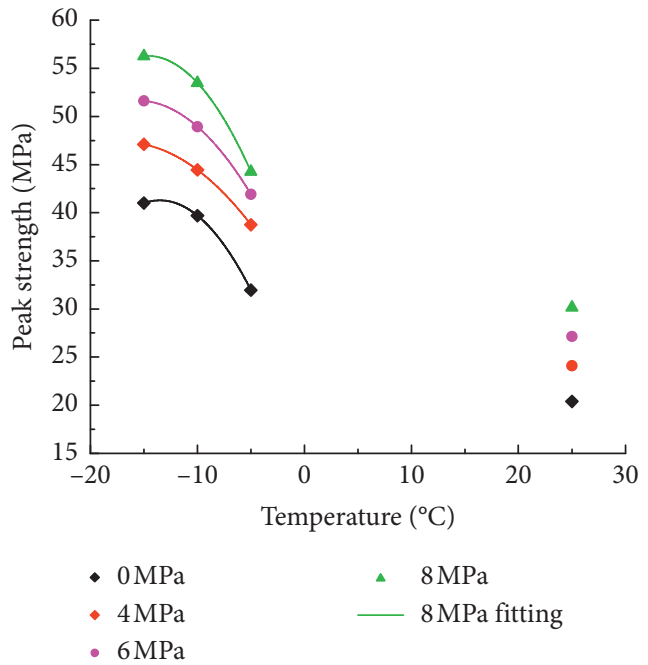

(a)

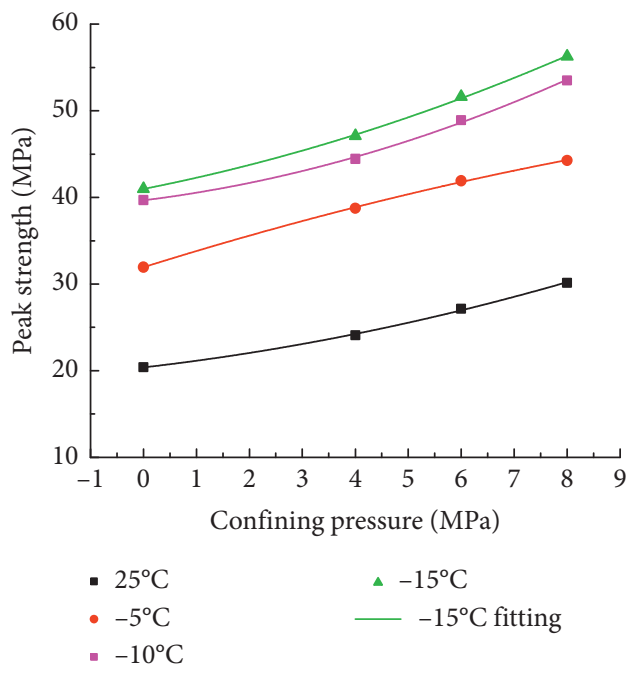

(b)

FIgURE 5: Peak strength curves under different conditions: (a) temperature and (b) confining pressure.

TABle 2: Cohesion and internal friction angle at different temperature.

\begin{tabular}{lcc}
\hline Temperature $\left({ }^{\circ} \mathrm{C}\right)$ & $c(\mathrm{MPa})$ & $\Phi\left(^{\circ}\right)$ \\
\hline 25 & 6.82 & 22.58 \\
-5 & 10.02 & 26.14 \\
-10 & 11.93 & 27.28 \\
-15 & 11.96 & 28.99 \\
\hline
\end{tabular}

temperature decreases from $-5^{\circ} \mathrm{C}$ to $-10^{\circ} \mathrm{C}$, and $10.51 \%$ from $-10^{\circ} \mathrm{C}$ to $-15^{\circ} \mathrm{C}$ (taking the pressure of $5 \mathrm{MPa}$ as an example). On the other hand, confining pressure also has a great influence on the elastic modulus (Figure 8(b)). At a stable temperature, the elastic modulus increases with confining pressure. For example, at $-5^{\circ} \mathrm{C}$ when the confining pressure increases, the elastic modulus increases by $35.07 \%$, $27.48 \%$, and $11.92 \%$ successively under the testing pressure intervals.
3.4.2. Maximum Axial Strains. Figure 9(a) shows that the maximum axial strain is greatly affected by temperature. Under stable confining pressure, the maximum axial strain decreases and brittleness is getting more and more obvious with the decreasing temperature. Under the condition of $0 \mathrm{MPa}$, when the temperature decreases from $25^{\circ} \mathrm{C}$ to $-15^{\circ} \mathrm{C}$, the maximum axial strain decreases from $1.24 \%$ to $0.93 \%$ with a reduction of $25.56 \%$. Similarly, the maximum axial strain decreases by $29.78 \%, 28.87 \%$, and $27.56 \%$, respectively, under the pressure of 4,6 , and $8 \mathrm{MPa}$ at the same temperature interval. However, the reduction rate declines with continuous decrease of temperature (below $-10^{\circ} \mathrm{C}$ ) under the condition of given confining pressure. Under the confining pressure of 0,4 , 6 , and $8 \mathrm{MPa}$, when the temperature decreases from $-5^{\circ} \mathrm{C}$ to $-10^{\circ} \mathrm{C}$, the maximum axial strain decreases by $11.76 \%, 16.12 \%$, $16.41 \%$, and $16.03 \%$, respectively, whereas when the temperature decreases from $-10^{\circ} \mathrm{C}$ to $-15^{\circ} \mathrm{C}$, it decreases by $2.11 \%$, $4.81 \%, 5.61 \%$, and $6.36 \%$, respectively. Confining pressure also 


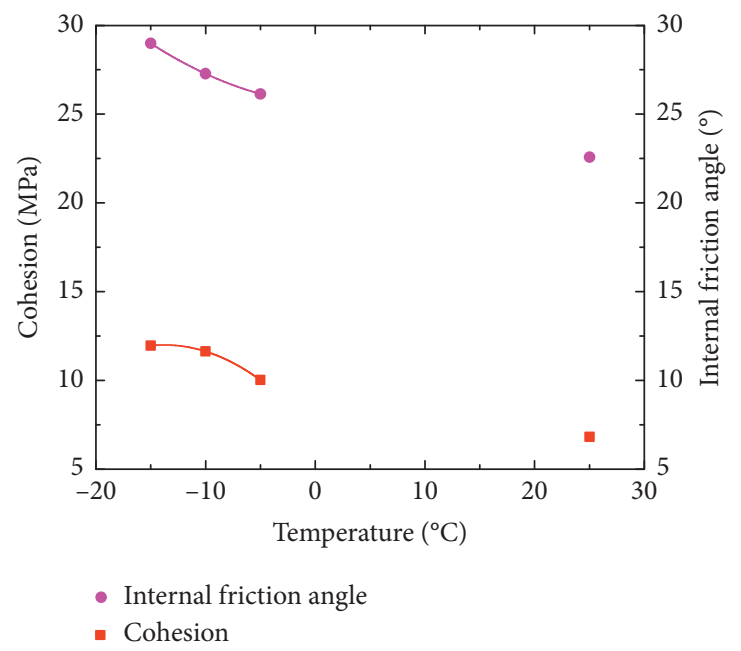

FiguRE 6: Cohesion and internal friction angle curves at different temperature.

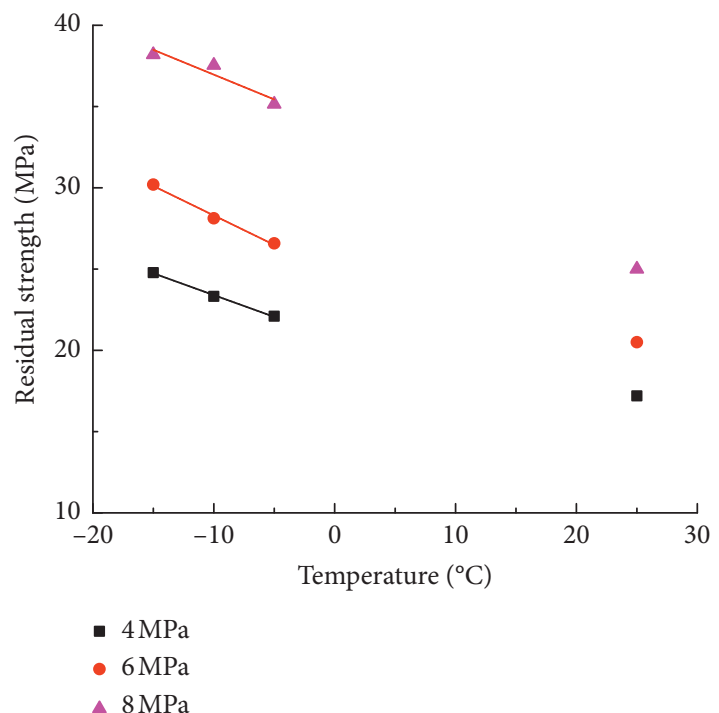

(a)

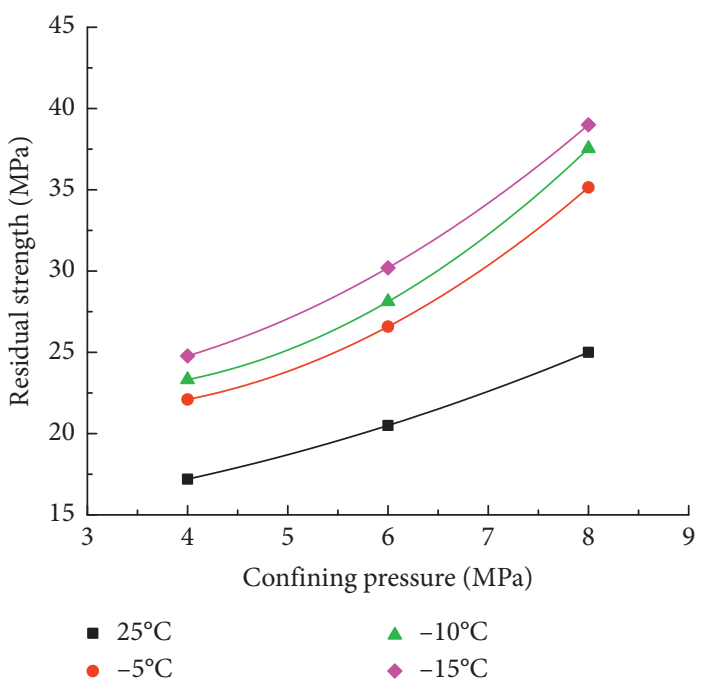

(b)

FIgURE 7: Residual strength curves under different conditions: (a) temperature and (b) confining pressure.

affects the maximum strain (Figure 9(b)). At a given temperature, the increase of confining pressure leads to a larger maximum strain with a time lag and lower brittleness. At the temperature of $-5^{\circ} \mathrm{C}$, the maximum axial strain increases by $24.43 \%$ and by $15.79 \%$ and $10.75 \%$ at $-10^{\circ} \mathrm{C}$ and $-15^{\circ} \mathrm{C}$, respectively, when the confining pressure increases from 0 to $8 \mathrm{MPa}$.

3.4.3. Strength Attenuation Behavior. Strength attenuation behavior of rocks can be described by the attenuation coefficient $D_{\mathrm{a}}[30]$ as follows:

$$
D_{\mathrm{a}}=\frac{\sigma_{\mathrm{p}}-\sigma_{\mathrm{r}}}{\sigma_{\mathrm{p}}}=\frac{\delta \sigma}{\sigma_{\mathrm{p}}}
$$

where $\sigma_{\mathrm{p}}, \sigma_{\mathrm{r}}$, and $\delta \sigma$ are the peak strength, residual strength, and strength attenuation of the rock, respectively. The strength attenuation coefficient of the rock under uniaxial compression is called the initial intensity attenuation coefficient and can be denoted as $D_{\mathrm{a} 0}$, which can be expressed as follows:

$$
D_{\mathrm{a} 0}=\frac{\delta \sigma_{\mathrm{u}}}{\sigma_{\mathrm{c}}},
$$

where $\delta \sigma_{\mathrm{u}}$ and $\sigma_{\mathrm{c}}$ are the strength attenuation under uniaxial compression and the uniaxial compressive strength of the rock, respectively. The value of strength attenuation under uniaxial compression is large, so that $D_{\mathrm{a} 0}$ can be considered to be close to 1 . The larger the attenuation coefficient of rock strength is, the greater the difference from peak strength to residual strength will be. On the contrary, the smaller the strength attenuation coefficient of the rock is, the lower the brittleness of the rock will be. So, to some extent, the attenuation coefficient of rock strength can reflect the brittleness of the rock. 


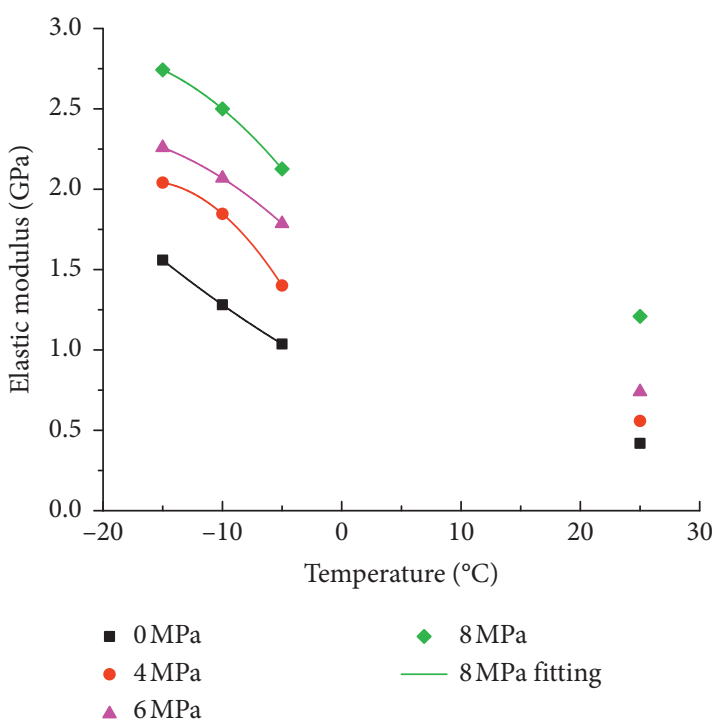

(a)

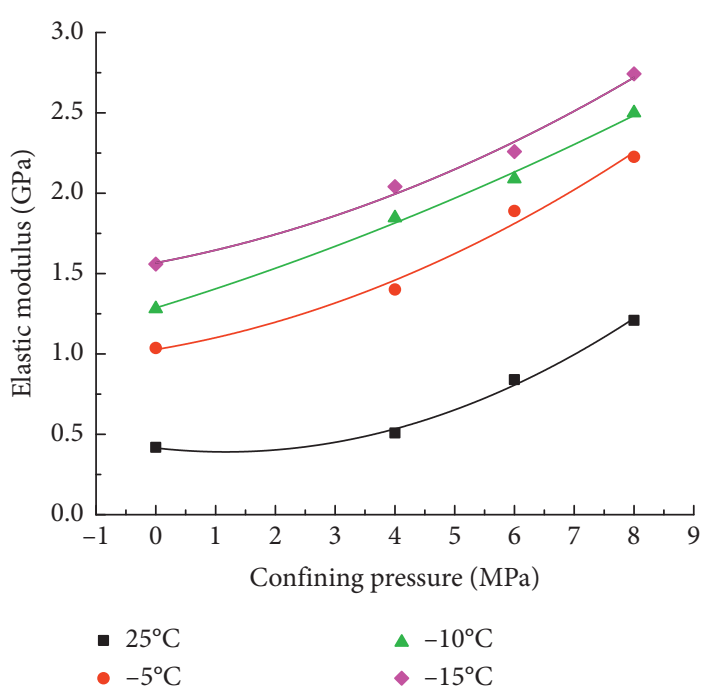

(b)

FiguRE 8: Elastic modulus curves under different conditions: (a) temperature and (b) confining pressure.

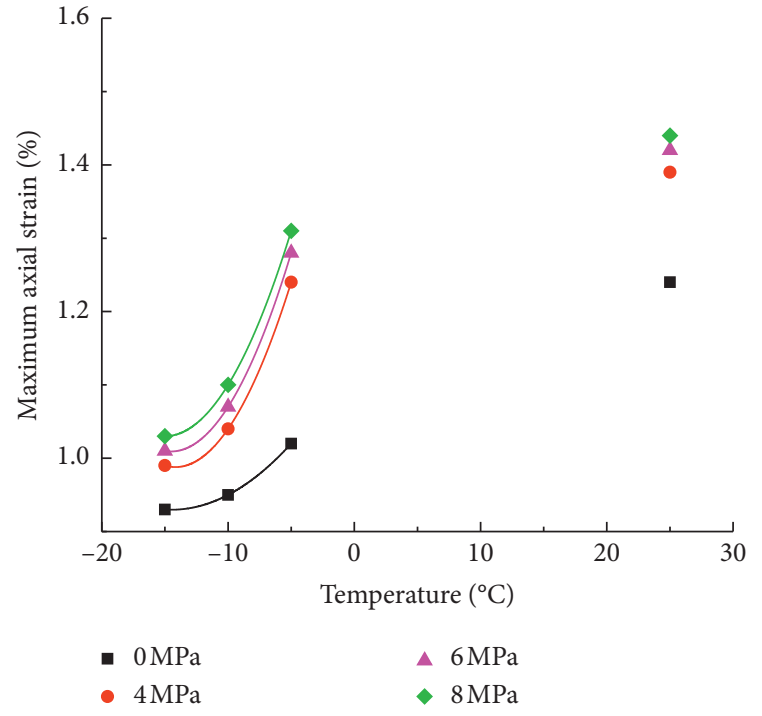

(a)

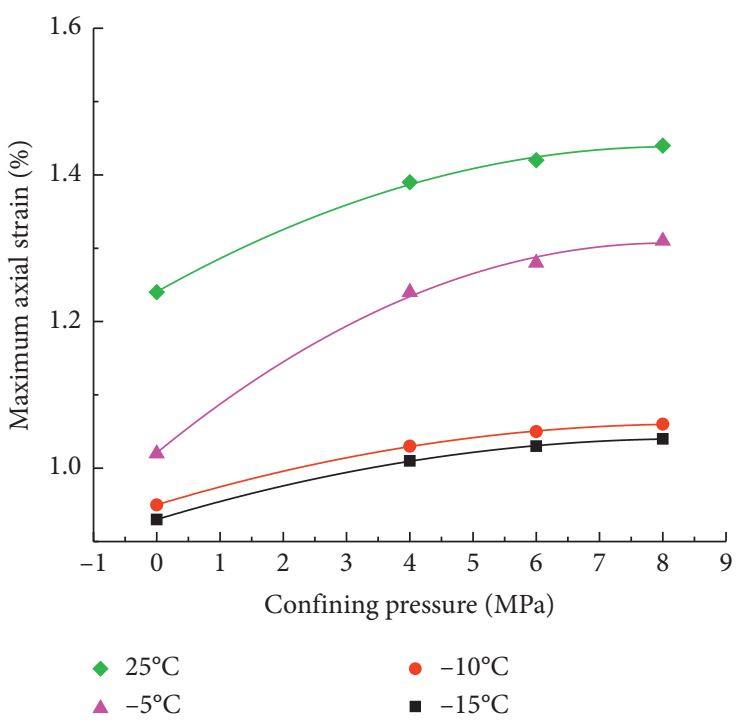

(b)

FIGURE 9: Maximum axial strain curves under different conditions: (a) temperature, and (b) confining pressure.

Based on the test results, according to equations (1) and (2), rock strength attenuation coefficients for different temperature and confining pressure can be obtained as given in Table 3.

Table 3 shows that freezing can promote brittleness of the Jurassic sandstone. At $25^{\circ} \mathrm{C}$, the range of rock strength attenuation coefficient is $0.171-1$ with an average value of 0.426 . At $-15^{\circ} \mathrm{C}$, the range is $0.333-1$ with an average value of 0.561 . When the temperature decreases from $25^{\circ} \mathrm{C}$ to $-15^{\circ} \mathrm{C}$, the average strength attenuation coefficient increases from 0.426 to 0.561 . The relationship between them is shown in Figure 10(a), and can be expressed by a polynomial equation. On the contrary, the brittleness of the Jurassic sandstone is reduced with increasing confining pressure. At $25^{\circ} \mathrm{C},-5^{\circ} \mathrm{C}$, $-10^{\circ} \mathrm{C}$, and $-15^{\circ} \mathrm{C}$, when the confining pressure rises from 0 to $8 \mathrm{MPa}$, the strength attenuation coefficient decreases by $0.829,0.794,0.701$, and 0.667 , respectively. A polynomial relationship can also be found between the strength attenuation coefficient and confining pressure (Figure 10(b)), which can be expressed as follows:

$$
D_{\mathrm{a}}=a+b \cdot p+c \cdot p^{2}
$$

where $D_{\mathrm{a}}$ and $p$ are the strength attenuation coefficient and confining pressure of the sample, respectively, and $a, b$, and $c$ are the fitting coefficients summarized in Table 4.

When temperature decreases, strength of the Jurassic sandstone increases, but the strength attenuation coefficient increases also. It means the plastic stage is shortened with 
TABLE 3: Rock strength attenuation coefficients of Jurassic sandstones.

\begin{tabular}{|c|c|c|c|c|c|}
\hline Temperature $\left({ }^{\circ} \mathrm{C}\right)$ & Confining pressure $(\mathrm{MPa})$ & $\delta \sigma(\mathrm{MPa})$ & $\sigma_{\mathrm{p}}(\mathrm{MPa})$ & $D_{\mathrm{a}}$ & $\overline{\overline{D_{\mathrm{a}}}}$ \\
\hline \multirow{4}{*}{25} & 0 & 20.4 & 20.4 & 1.000 & \multirow{4}{*}{0.426} \\
\hline & 4 & 6.9 & 24.1 & 0.286 & \\
\hline & 6 & 6.65 & 27.15 & 0.245 & \\
\hline & 8 & 5.15 & 30.15 & 0.171 & \\
\hline \multirow{4}{*}{-5} & 0 & 31.96 & 31.96 & 1.000 & \multirow{4}{*}{0.500} \\
\hline & 4 & 16.65 & 38.76 & 0.430 & \\
\hline & 6 & 15.34 & 41.92 & 0.366 & \\
\hline & 8 & 9.12 & 44.27 & 0.206 & \\
\hline \multirow{4}{*}{-10} & 0 & 39.7 & 39.7 & 1.000 & \multirow{4}{*}{0.548} \\
\hline & 4 & 20.78 & 44.1 & 0.471 & \\
\hline & 6 & 20.38 & 48.5 & 0.420 & \\
\hline & 8 & 16 & 53.5 & 0.299 & \\
\hline \multirow{4}{*}{-15} & 0 & 41 & 41 & 1.000 & \multirow{4}{*}{0.561} \\
\hline & 4 & 23.4 & 48.1 & 0.486 & \\
\hline & 6 & 22.42 & 52.62 & 0.426 & \\
\hline & 8 & 19.08 & 57.28 & 0.333 & \\
\hline
\end{tabular}

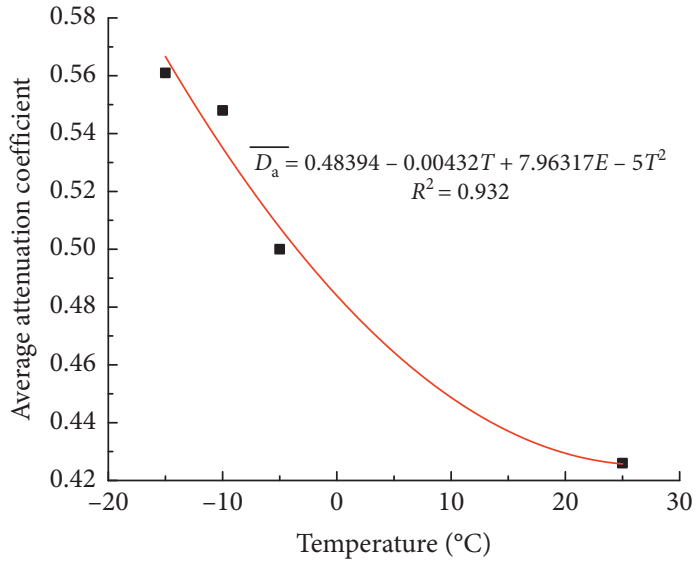

(a)

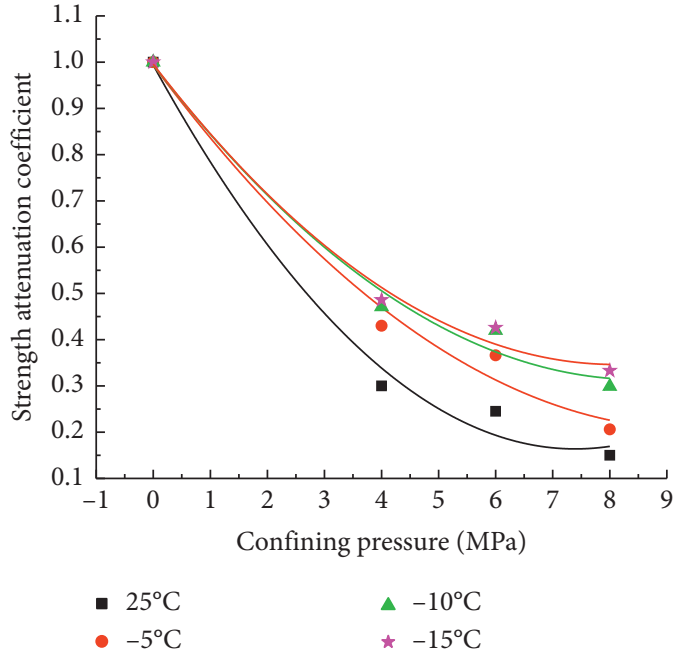

(b)

Figure 10: Attenuation coefficients curves under different conditions: (a) temperature, and (b) confining pressure.

higher brittleness and insufficient capacity of the plastic deformation reserve. Once the rock enters the plastic stage, it will be destroyed easily. Therefore, more attention should be paid in the design of freezing engineering.

\section{Micromechanism Analysis of the Changes in Mechanical Properties of Jurassic Sandstone}

4.1. Porosity Based on NMR Test. The pore-throat size plays an important role in the freezing of sandstone. The values of porosity and pore-throat size distribution of saturated samples at different temperature are shown in Table 5.

Table 5 shows porosity decreases with the decreasing temperature. The value of porosity is $1.17 \%$ with $1.12 \%$ small pore-throats and $0.05 \%$ large pore-throats at $-10^{\circ} \mathrm{C}$, and large pore-throats vanish at $-15^{\circ} \mathrm{C}$. Porosity decreases sharply when the temperature decreases from $25^{\circ} \mathrm{C}$ to $-10^{\circ} \mathrm{C}$; meanwhile, the peak strength increases greatly, while the reduction rate and the growth rate both decline when the temperature decreases from $-10^{\circ} \mathrm{C}$ to $-15^{\circ} \mathrm{C}$. So, changes in porosity bring the changes in strength of the frozen rock.

4.2. Formation of Pore (Crack) Ice Crystals. The microstructure evolution is manifested by macrocosmic mechanical properties [31]. Internal pores and pore-throat size affect the freezing process of liquid water in rocks. The freezing process of rock can be divided into different stages according to the increment of ice crystals in pore-throats [32]. Based on microcharacteristics of the rock samples (Figure 3), the sketch of microstructure could be obtained (Figure 11(a)). Based on NMR test results (Table 5), the freezing process of water in pore-throats can go through three stages: (1) rapid freeze stage with the temperature range of 0 to $-5^{\circ} \mathrm{C}$. During this stage, violent phase transitions of water may occur inside rocks. Porosity decreases and larger pore-throat size disappears rapidly. Most of the 
TABLE 4: Fitting coefficients for the strength attenuation coefficient at different temperatures.

\begin{tabular}{lcccc}
\hline Temperature $\left({ }^{\circ} \mathrm{C}\right)$ & $a$ & $b$ & $c$ & $R^{2}$ \\
\hline 25 & 0.9941 & -0.2242 & 0.0158 & 0.994 \\
-5 & 0.9934 & -0.1658 & 0.0089 & 0.959 \\
-10 & 0.9943 & -0.1589 & 0.0090 & 0.962 \\
-15 & 0.9961 & -0.1602 & 0.0097 & 0.975 \\
\hline
\end{tabular}

TABLE 5: Porosity and pore-throat size distribution and peak strength.

\begin{tabular}{lccc}
\hline Temperature $\left({ }^{\circ} \mathrm{C}\right)$ & Peak strength $(8 \mathrm{MPa})$ & Porosity $(\%)$ & \multicolumn{2}{c}{ Pore-throat size distribution $(\%)$} \\
$0-1000 \mu \mathrm{m}$
\end{tabular}

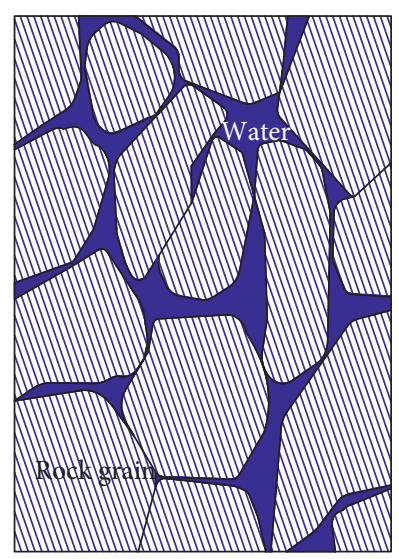

(a)

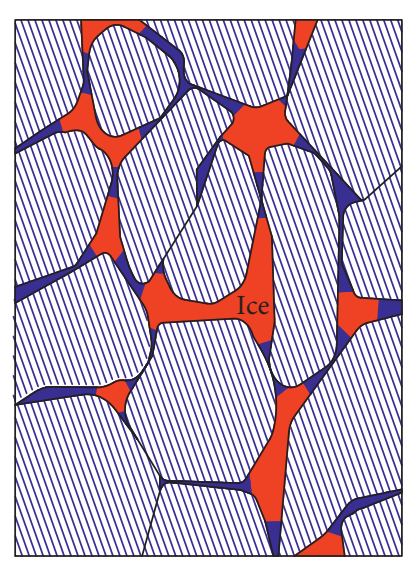

(b)

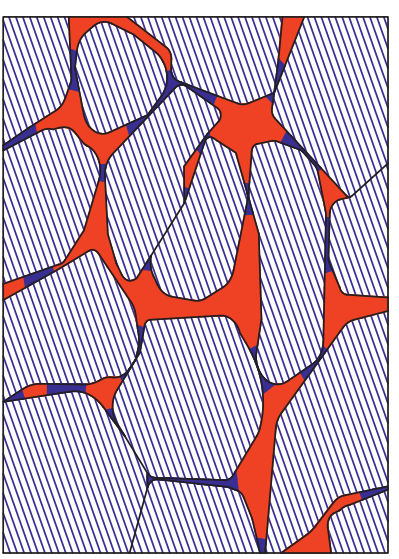

(c)

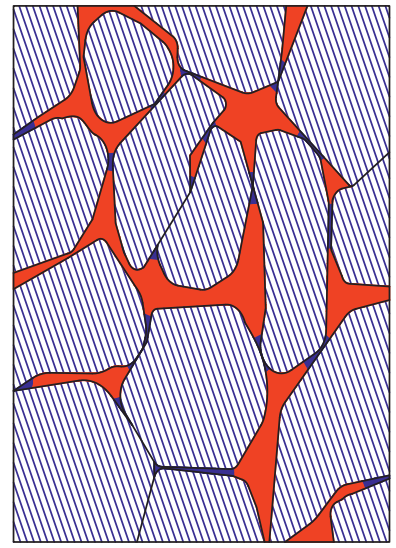

(d)

Figure 11: Formation process of pore (crack) ice during freezing: (a) $25^{\circ} \mathrm{C}$, (b) $-5^{\circ} \mathrm{C}$, (c) $-10^{\circ} \mathrm{C}$, and (d) $-15^{\circ} \mathrm{C}$.

liquid water mainly in the large pore-throats has been turned into ice. The ice crystal content of pores (cracks) increases rapidly (Figure 11(b)). (2) Freeze developing stage with the corresponding temperature range of $-5^{\circ} \mathrm{C}$ to $-10^{\circ} \mathrm{C}$. During this stage, liquid water in small pore-throats and some fine (micro) pore-throats has been turned into ice and ice crystal content in pores (cracks) continues to increase, but the growth rate declines (Figure 11(c)). The porosity and the mount of small pore-throats decrease continuously. (3) Freezing stable stage with the temperature below $-10^{\circ} \mathrm{C}$. During this stage, porosity and pore-throat size distribution vary little because most liquid water in the pore (crack) has been frozen; however, due to capillary force and surface adsorption of mineral grains, there is still water which cannot be frozen with relatively lower freezing point. Therefore, even if some liquid water mainly in fine (micro) pore-throats continues to be frozen, the increment of pore (crack) ice crystals is very small (Figure 11(d)).

4.3. Microcosmic Interpretation of Changes in Rock Mechanical Properties. It is revealed by the test results that temperature, especially subzero temperature, has a great impact on the strength and deformation characteristics of the Jurassic sandstone. Figure 11 shows that freezing process is substantially correlated to the variation of the pore-throat size. During the rapid freeze stage and the freeze developing stage, the pores (cracks) are filled with a large number of ice crystals, so the pore-throat radius decreases significantly. Rock grains are connected tightly with high cohesive force, which improves the rock's ability to resist deformation. In addition, the strength of ice crystals contributes to the rock strength. Therefore, elastic modulus and strength are greatly increased. During the third stage with temperature below $-10^{\circ} \mathrm{C}$, the increment of ice is very small and porosity and pore-throat size vary little (Figures 11(c) vs. 11(d)). The effect of grains shrinkage is not obvious at the same time. The increase of rock strength as one of the macrocosmic performance tends to slow down and be stable eventually. Different confining pressure and temperature may lead to different friction effect on rock grains and ice crystals, which causes diverse fracture patterns of testing samples. The rise of confining pressure may limit the expansion of internal cracks in rocks, enhance the closure effect of cracks, and 
reduce the slip between grains, which may contribute to the rise of elastic modulus and strength. Meanwhile, the rise of confining pressure also can delay the peak strength and result in an increasing maximum axial strain.

Low temperature and confining pressure can greatly change microstructure characteristics of rock, which leads to the diversity of macromechanical properties.

\section{Conclusions}

Taking the Jurassic sandstone in Western China as an example, rock strength and deformation characteristics as well as the influencing mechanism of confining pressure and temperature were analyzed by the triaxial compression test and NMR test under different conditions.

(1) Strength parameters such as peak strength, residual strength, cohesion, and internal friction angle tended to increase with the decreasing temperature when the confining pressure was fixed. Similarly, the above parameters increased with the confining pressure at a specified temperature. The increment appeared to be especially obvious at subzero temperature, while the strength growth rate declined at colder temperature (below $-10^{\circ} \mathrm{C}$ ).

(2) Elastic modulus increased with the decreasing temperature under stable confining pressure, while the growth rate declined at colder temperature (below $-10^{\circ} \mathrm{C}$ ). There is a positive correlation between elastic modulus and confining pressure at a stable temperature. Under stable confining pressure, the maximum axial strain decreased and brittleness increased with the decrease of temperature. At a stable temperature, the increase in confining pressure led to a larger maximum strain with a time lag and lower brittleness.

(3) Average strength attenuation coefficients increased from 0.426 to 0.561 when the temperature decreased from $25^{\circ} \mathrm{C}$ to $-15^{\circ} \mathrm{C}$, while strength attenuation coefficients decreased with the increasing confining pressure at a certain temperature.

(4) During the first two stages of freezing, pores (cracks) of the rock were filled with a large number of ice crystals with significant decrease of porosity and pore-throat radius, whereas the increment of ice is very small during the third stage with the temperature below $-10^{\circ} \mathrm{C}$, which could explain why the growth rate of rock strength would slow down at colder temperature.

\section{Data Availability}

The data used to support the finding of this study are provided in this paper.

\section{Conflicts of Interest}

The authors declare no conflicts of interest regarding this paper.

\section{Acknowledgments}

This research was supported by the National Natural Science Foundation of China (grant no. 51874005) and the Educational Commission of Anhui Province of China (KJ2019A0739).

\section{References}

[1] Z. M. Xu, S. Gao, Y. J. Sun et al., "A study of conditions of water bearing media and water dynamics in typical Jurassic coal rich regions in Western," China Journal of China Coal Society, vol. 42, no. 2, pp. 444-451, 2017.

[2] L. M. Fan and X. D. Ma, "Research progress of water inrush hazard in shallow buried coal seam mine," Coal Science and Technology, vol. 44, no. 1, pp. 8-12, 2016.

[3] Q. B. Meng, L. J. Han, H. Pu et al., "Research and monitoring analysis of coal roadway bolting system in very weakly cemented stratum," Journal of China Coal Society, vol. 41, no. 1, pp. 234-245, 2016.

[4] L. H. Sun, H. G. Ji, and B. S. Yang, "Physical and mechanical characteristic of rocks with weakly cemented strata in Western representative mining," Journal of China Coal Society, vol. 44, no. 3, pp. 865-873, 2019.

[5] J. B. Liu, J. Zhao, and Z. X. Zhu, "On the number of spanning trees and normalized Laplacian of linear octagonal-quadrilateral networks," International Journal of Quantum Chemistry, vol. 119, no. 17, Article ID e25971, 2019.

[6] J.-B. Liu, J. Zhao, and Z.-Q. Cai, "On the generalized adjacency, Laplacian and signless Laplacian spectra of the weighted edge corona networks," Physica A: Statistical Mechanics and Its Applications, vol. 540, Article ID 123073, 2020.

[7] T. Yamabe and K. M. Neaupane, "Determination of some thermo-mechanical properties of Sirahama sandstone under subzero temperature condition," International Journal of Rock Mechanics and Mining Sciences, vol. 38, no. 7, pp. 1029-1034, 2001.

[8] C. Park, J. H. Synn, H. S. Shin, D. S. Cheon, H. D. Lim, and S. W. Jeon, "Experimental study on the thermal characteristics of rock at low temperatures," International Journal of Rock Mechanics and Mining Sciences, vol. 41, no. 1, pp. 81-86, 2004.

[9] G. M. Xu, Q. S. Liu, W. W. Peng, and X. X. Chang, "Experimental study on basic mechanical behaviors of rocks under low temperatures," Chinese Journal of Rock Mechanics and Engineering, vol. 25, no. 12, pp. 2502-2508, 2006.

[10] Q. S. Liu, G. M. Xu, Y. H. Hu, and X. Chang, "Study on basic mechanical behaviors of rocks at low temperatures," Key Engineering Materials, vol. 306-308, pp. 1479-1484, 2006.

[11] Y. P. Li and Z. Y. Wang, "Uniaxial compressive mechanical properties of rock at low temperature," Journal of University of Science and Technology Beijing, vol. 33, no. 6, pp. 671-675, 2011.

[12] Y. P. Li and Z. Y. Wang, "Study of parameters and strength of thermal effects for granite under low temperature," Rock and Soil Mechanics, vol. 33, no. 2, pp. 321-326, 2012.

[13] J. Kodama, T. Goto, Y. Fujii, and P. Hagan, "The effects of water content, temperature and loading rate on strength and failure process of frozen rocks," International Journal of Rock Mechanics and Mining Sciences, vol. 62, no. 2, pp. 1-13, 2013.

[14] G. S. Yang, Q. S. Zhang, and Y. B. Pu, "Preliminary study on meso-damage propagation characteristics of rock under condition of freezing temperature," Rock and Soil Mechanics, vol. 25, no. 9, pp. 1409-1412, 2004. 
[15] G. S. Yang, J. M. Xi, H. J. Li, and L. Cheng, "Experimental study of rock mechanical properties under triaxial compressive and frozen conditions," Chinese Journal of Rock Mechanics and Engineering, vol. 29, no. 3, pp. 459-464, 2010.

[16] G. S. Yang, J. M. Xi, X. M. Shao, H. J. Li, and L. Cheng, "Experimental study on rock strength properties under freezing conditions," Journal of Xi'an University of Science and Technology, vol. 30, no. 1, pp. 14-18, 2010.

[17] G. S. Yang, J. M. Xi, Z. J. Wang, L. Cheng, and H. J. Li, “Study on rock mechanical properties of frozen wall of main shaft in Hujiahe coal mine," Journal of China Coal Society, vol. 35, no. 4, pp. 565-570, 2010.

[18] G. S. Yang and L. X. Tao, "Experimental study on the sandy mudstone mechanical properties of shaft sidewalls under the frozen conditions," Journal of Mining \& Safety Engineering, vol. 29, no. 4, pp. 492-496, 2012.

[19] G. S. Yang, J. M. Xi, H. J. Li, L. Cheng, and X. T. Lv, "Experimental study on the mechanical properties of soft rock of coal mine shaft sidewalls under the frozen conditions," Chinese Journal of Underground Space and Engineering, vol. 8, no. 4, pp. 690-687, 2012.

[20] G. S. Yang, Y. L. Qu, and X. J. Mi, "Study of mechanical properties and temperature field of frozen wall in Cretaceous strata," Chinese Journal of Rock Mechanics and Engineering, vol. 33, no. 9, pp. 1873-1879, 2014.

[21] G. S. Yang, Y. Wei, Y. J. Shen et al., "Mechanical behavior and strength forecast model of frozen saturated sandstone under triaxial compression," Chinese Journal of Rock Mechanics and Engineering, vol. 38, no. 4, pp. 683-694, 2019.

[22] D. W. Li, R. H. Wang, and J. H. Fan, "Nonlinear rheological model for frozen soft rock during Cretaceous period," Chinese Journal of Geotechnical Engineering, vol. 33, no. 3, pp. 98-403, 2011.

[23] Y. Liu, R. H. Wang, and J. H. Chen, "Experiment study on physical mechanics performances of Cretaceous system rock under minus temperature," Coal Mine Engineering, vol. 1, pp. 82-84, 2011.

[24] J. M. Xi, G. S. Yang, L. Pang, X. T. Lv, and F. L. Liu, "Experimental study on basic mechanical behaviors of sandy mudstone under low freezing temperature," Journal of China Coal Society, vol. 39, no. 7, pp. 1262-1268, 2014.

[25] F. Zi, G. S. Yang, and H. L. Jia, "Influence of saturation degree on the mechanical properties of frozen argillaceous siltstone," Journal of Glaciology and Geocryology, vol. 40, no. 4, pp. 748-755, 2018.

[26] B. Liu, Y. J. Ma, H. L. Sheng, H. L. Deng, Q. Han, and Y. J. Cao, "Experimental study on mechanical properties of cretaceous red sandstone under different freezing temperatures and confining pressures," Chinese Journal of Rock Mechanics and Engineering, vol. 38, no. 3, pp. 455-465, 2019.

[27] G. Zhang, B. Liu, Y. J. Ma, and Y. C. Liu, "Mechanical analysis on sandy mudstone in uniaxial compression and acoustic emission test through artificial freezing method," Chinese Journal of Underground Space and Engineering, vol. 15, no. 3, pp. 699-706, 2019.

[28] A. Török, A. Ficsor, M. Davarpanah, and B. Vásárhelyi, "Comparison of mechanical properties of dry, Saturated and frozen porous rocks," in IAEG/AEG Annual Meeting Proceedings, San Francisco, California, 2018-Volume 6, A. Shakoor and K. Cato, Eds., Springer, Cham, Switzerland, pp. 455-465, 2018.

[29] H. Yang, J. X. Zhang, R. L. Shan, F. M. Wu, and Z. M. Guo, "Experimental study on mechanical properties of frozen saturated single fractured rock mass," Rock and Soil Mechanics, vol. 39, no. 4, pp. 1245-1255, 2018.

[30] J. Peng, G. Rong, M. Cai, and K. Peng, "Determination of residual strength of rocks by a brittle index," Rock and Soil Mechanics, vol. 36, no. 2, pp. 403-408, 2015.

[31] Z. L. Zhang and Z. D. Cui, "Analysis of microscopic pore structures of the silty clay before and after freezing-thawing under the subway vibration loading," Environmental Earth Sciences, vol. 76, no. 15, p. 528, 2017.

[32] H. Liu, G. S. Yang, H. L. Jia et al., "Experimental study on meso-structure of rock in the process of crack (pore) water freezing," Chinese Journal of Rock Mechanics and Engineering, vol. 35, no. 12, pp. 2516-2524, 2016. 